\section{ACKNOWLEDGMENTS}

I thank E. Jenkinson and C. Sanders for useful discussions and am supported by a Biotechnology and Biological Sciences Research Council David Phillips Research Fellowship.

1. Tye, B.K. Annu. Rev. Biochem. 68, 649-686 (1999).

2. Ishimi, Y. J. Biol. Chem. 272, 24508-24513 (1997)

3. Kaplan, D.L., Davey, M.J. \& O'Donnell, M. J. Biol. Chem. 278, 49171-49182 (2003)

4. Lee, J.K. \& Hurwitz, J. J. Biol. Chem. 275, $18871-$ 18878 (2000)

5. Chong, J.P., Hayashi, M.K., Simon, M.N., Xu, R.M. \& Stillman, B. Proc. Natl. Acad. Sci. USA 97, 15301535 (2000)

6. Grainge, I., Scaife, S. \& Wigley, D.B. Nucleic Acids Res. 31, 4888-4898 (2003).
7. Kelman, Z., Lee, J.K. \& Hurwitz, J. Proc. Natl. Acad. Sci. USA 96, 14783-14788 (1999)

8. Poplawski, A., Grabowski, B., Long, S.E. \& Kelman, Z. J. Biol. Chem. 276, 49371-49377 (2001).

9. Pucci, B., De Felice, M., Rossi, M., Onesti, S. \& Pisani, F.M. J. Biol. Chem. 279, 49222-49228 (2004).

10. Shechter, D.F., Ying, C.Y. \& Gautier, J. J. Biol. Chem. 275, 15049-15059 (2000)

11. McGeoch, A.T., Trakselis, M.A., Laskey, R.A. \& Bell, S.D. Nat. Struct. Mol. Biol. 12, 756-762 (2005)

12. Iyer, L.M., Leipe, D.D., Koonin, E.V. \& Aravind, L. J. Struct. Biol. 146, 11-31 (2004).

13. Blow, J.J. \& Dutta, A. Nat. Rev. Mol. Cell Biol. 6, 476 486 (2005).

14. Takahashi, T.S., Wigley, D.B. \& Walter, J.C. Trends Biochem. Sci. 30, 437-444 (2005)

15. Singleton, M.R., Sawaya, M.R., Ellenberger, T. \& Wigley, D.B. Cell 101, 589-600 (2000).
16. Gai, D., Zhao, R., Li, D., Finkielstein, C.V. \& Chen, X.S Cell 119, 47-60 (2004).

17. Li, D. et al. Nature 423, 512-518 (2003).

18. Shen, J., Gai, D., Patrick, A., Greenleaf, W.B. \& Chen, X.S. Proc. Natl. Acad. Sci. USA 102, 11248 11253.

19. Fletcher, R.J. et al. Nat. Struct. Biol. 10, 160-167 (2003).

20. Pape, T. et al. EMBO Rep. 4, 1079-1083 (2003).

21. Blow, J.J., Dilworth, S.M., Dingwall, C., Mills, A.D. \& Laskey, R.A. Phil. Trans. R. Soc. Lond. B 317, 483894 (1987).

22. Fodje, M.N. et al. J. Mol. Biol. 311, 111-122 (2001).

23. Neuwald, A.F., Aravind, L., Spouge, J.L. \& Koonin, E.V. Genome Res. 9, 27-43 (1999).

24. Gorbalenya, A.E. \& Koonin, E.V. Curr. Opin. Struct. Biol. 3, 419-429 (1993).

\title{
A toxin activator
}

Cholera is a severe diarrheal disease caused by the bacterium Vibrio cholerae. After colonizing the small intestine, the bacterium secretes a virulence factor called cholera toxin. The holotoxin contains five binding (B) subunits, an active ( $A 1$ ) subunit, and a bridging piece (A2) that links

A1 to the five $B$ subunits.

Once it enters the cell, the

Al subunit enzymatically transfers ADP-ribose from NAD to a $G$ protein, $\mathrm{G}_{\mathrm{s} \alpha}$. ADPribosylated $\mathrm{G}_{\mathrm{s} \alpha}$ constitutively activates adenylate cyclase located on the inner side of the cytoplasmic membrane, increasing cyclic AMP levels. This leads to electrolyte and water loss into the gut lumen, creating the diarrhea characteristic of cholera.

The $A 1$ subunit of cholera toxin (CTA1) alone has relatively low ADP-ribosylation activity in vitro. However, the activity of the enzyme is increased through its interaction with ADP-ribosylation factor (ARF), a G-protein from the human host. ARFs are essential guanine-nucleotide binding proteins involved in membrane trafficking and remodeling of the actin cytoskeleton. ARFs interact with a myriad of host proteins but it is not clear how they bind to and activate CTA1. In a recent a paper in Science O'Neal et al. determined the structure of ARF6-GTP bound to a CTA1 variant (Science 309, 1093-1096, 2005). The structure indicates that the bacterial toxin has co-opted the protein binding properties of ARF to achieve increased enzymatic activity.

One of the most striking features of the ARF6-GTP-CTA1 complex is that the bacterial toxin binds to the same surface used by ARF-GTP (yellow ribbons) to recognize its native human partners. This surface is characteristic of protein-protein interfaces in that it is hydrophobic and flat. ARF proteins contain the switch I, switch II and interswitch motifs that differ in conformation between GDP- and GTP-bound states and are used to interact with
ARF partner proteins. Only ARF-GTP can bind and activate cellular targets. The structure of ARF6-GTP-CTA1 reveals that ARF6-GTP uses conserved residues from all three switch regions to interact with conserved residues on the face of CTA1 (colored surface) that in holotoxin interacts with CTA2 (blue helix). These interactions convert the so-called activation loop of CTA1 from an ordered coil to an $\alpha$-helix and facilitate the displacement of a loop that occludes the active site in holotoxin to expose residues implicated in substrate binding and catalysis. Hence, ARF6-GTP induces conformational changes within CTA1 that make it a more efficient enzyme. However, as seen in other ARF-protein complexes, ARF6-GTP does not change conformation upon binding CTA1. The similarities between ARF6-GTP-CTA1 and other ARF complexes are unexpected considering the interspecies nature of the toxin-ARF complex, and suggest that CTA1 has evolved to mimic the interactions of human effector proteins with ARFs.

How do the structural changes within CTA1 activate it to interact with $\mathrm{G}_{\mathrm{s} \alpha}$, its target in the infected host? Very little is known about CTA1 binding to $G_{s \alpha}$. However, the structures of other ADPribosylating toxins with NAD identified an ADP-ribosylating turnturn motif (ARTT) that may be involved in target protein binding, suggesting that $\mathrm{G}_{\mathrm{s} \alpha}$ may bind near the ARTT motif in the CTA1 active site. In the structure of ARF6-GTP-CTA1, the movement of the active-site loop not only opens the active site but also creates a knob next to the ARTT motif, providing a potential binding surface near the active site. Thus the conformational changes induced by interaction with one human G-protein, ARF, may facilitate CTA1 to recognize another human $\mathrm{G}$-protein: its substrate $\mathrm{G}_{\mathrm{s} \alpha}$. Further studies are needed to verify this hypothesis.

Evelyn Jabri 